\title{
Chronic partial unloading restores $\beta$-adrenergic responsiveness and reverses receptor downregulation in failing rat hearts
}

\author{
Jian Wang, MD, ${ }^{\text {a }}$ Masaki Tsukashita, MD, ${ }^{\text {a }}$ Takeshi Nishina, MD, PhD, ${ }^{\text {a }}$ Akira Marui, MD, PhD, ${ }^{a}$ Eiji Yoshikawa, MD,
} Hiroyuki Muranaka, MD, ${ }^{a}$ Satoshi Matsuoka, MD, $\mathrm{PhD},{ }^{\mathrm{b}}$ and Tadashi Ikeda, MD, $\mathrm{PhD}^{\mathrm{a}}$

\begin{abstract}
Objectives: Mechanical unloading with a left ventricular assist device promotes "reverse remodeling," including restoration of $\beta$-adrenergic receptor signaling and function. We compared the effects of partial unloading and complete unloading on $\beta$-adrenergic responsiveness and gene expressions in failing rat hearts by use of heterotopic heart-lung or heart transplantation models.
\end{abstract}

\begin{abstract}
Methods: Four weeks after ligation of the left anterior descending artery in Lewis rats, rats with heart failure were divided into 3 groups: infarcted hearts and lungs transplanted into the recipient rats (heart failure-partial unloading, $\mathrm{n}=8$ ); infarcted hearts transplanted into the recipient rats (heart failure-complete unloading, $\mathrm{n}=7$ ); infarcted (heart failure, $\mathrm{n}=8$ ) hearts without transplantation. Normal rats $(\mathrm{n}=7)$ were used as controls. Papillary muscle function and gene expressions were studied at 2 or 4 weeks after transplantation.
\end{abstract}

Results: In 2-week models, baseline developed tension of papillary muscles significantly increased in heart failure-partial unloading and heart failure-complete unloading compared with heart failure $(0.15 \pm 0.07$ and $0.12 \pm 0.05 \mathrm{~g} / \mathrm{mm}^{2}$ vs $\left.0.02 \pm 0.01 \mathrm{~g} / \mathrm{mm}^{2}, P<.05\right)$. However, in 4-week models, they decreased to $0.11 \pm 0.03$ and $0.10 \pm 0.03 \mathrm{~g} / \mathrm{mm}^{2}$. In 4-week but not in 2-week models, the increase from baseline in baseline developed tension produced by $\beta$-adrenergic stimulation (isoproterenol, $10^{-8}$ and $10^{-7} \mathrm{~mol} / \mathrm{L}$ ) was significantly increased in heart failure-partial unloading compared with heart failure-complete unloading and heart failure $(P<.05)$. The mRNA expressions of brain natriuretic peptide and $\beta_{1^{-}}$and $\beta_{2}$-adrenergic receptors were normalized in both 2- and 4-week models of heart failure-partial unloading.

Conclusions: Chronic partial unloading but not complete unloading improved $\beta$-adrenergic responsiveness and normalized brain natriuretic peptide and $\beta_{1^{-}}$and $\beta_{2}$-adrenergic receptor mRNA expressions in the failing rat hearts.

Recent evidence indicates that hemodynamic unloading and left ventricle rest via left ventricular (LV) assist devices (LVADs) can lead to normalization of myocardial structure and function in patients with end-stage heart failure (HF), which is known as "reverse remodeling." "1,2 In some cases, LVADs can eventually be explanted, and heart transplantation is no longer necessary. ${ }^{3}$ Although the functional outcomes of LVAD-induced unloading are described, clinical success of achieving sustained recovery of the end-stage failing heart has been sporadic, and the mechanisms of an LVAD as a bridge to recovery remain unknown.

On the other hand, to investigate the effects of mechanical unloading of the left ventricle, other than studies of human heart samples at the time of transplantation, some animal studies of heterotopic heart transplantation (ie, complete unloading) model have examined the effects of LV unloading on the failing hearts. ${ }^{4,5}$ However, no blood is drained into the

\footnotetext{
From the Departments of Cardiovascular Surgery ${ }^{\mathrm{a}}$ and Physiology and Biophysics, ${ }^{\mathrm{b}}$ Graduate School of Medicine, Kyoto University, Kyoto, Japan.

Received for publication March 6, 2008; revisions received July 15, 2008; accepted for publication Aug 19, 2008.

Address for reprints: Masaki Tsukashita, MD, Department of Cardiovascular Surgery, Graduate School of Medicine, Kyoto University, Sakyo-ku, Kyoto 606-8507, Japan (E-mail: mtsuka@kuhp.kyoto-u.ac.jp).

J Thorac Cardiovasc Surg 2009;137:465-70

$0022-5223 / \$ 36.00$

Copyright (C) 2009 by The American Association for Thoracic Surgery

doi:10.1016/j.jtcvs.2008.08.033
}

left heart cavities in that model; therefore, the left heart cavities were entirely shunted, and the left ventricle was completely unloaded. Recently, a new heterotopic heart-lung transplantation (ie, partial unloading) model was reported to simulate the mechanical unloading. ${ }^{6}$ In this model, the left ventricle was loaded only with the coronary venous blood, which creates partial unloading. In our previous study, ${ }^{7}$ we examined the effects of partial unloading on failing rat heart in a 2-week model. However, long-term effects of partial unloading and the differences to complete unloading are unknown. In this study, we compared contractility of isolated papillary muscle at baseline and after inotropic stimulation by isoproterenol, as well as gene expressions in failing rat hearts under partial unloading and complete unloading in both 2- and 4-week models.

\section{MATERIALS AND METHODS}

\section{Animal Model}

Inbred male Lewis rats weighing 150 to $200 \mathrm{~g}$ (Japan SLC Inc, Hamamatsu, Japan) were used in this study. All animals were bred under climate-controlled conditions with 12-hour light-dark cycle and provided with standardized rat chow and water. All experimental procedures were humanely performed according to the institutional guidelines on animal experimentation of Kyoto University.

HF Model. HF was induced by the ligation of left anterior descending (LAD) artery as previously described. ${ }^{5}$ In brief, Lewis rats were anesthetized with $1 \%$ isoflurane on a volume-cycled ventilator for small animals. 


$\begin{aligned} & \text { Abbreviations and Acronyms } \\ & \text { ANOVA } \text { analysis of variance } \\ & \text { AR }=\text { adrenergic receptor } \\ & \text { BNP }=\text { brain natriuretic peptide } \\ & \text { DT }=\text { development tension } \\ & \text { FAC }=\text { fractional area change } \\ & \text { GAPDH }=\text { glyceraldehyde 3-phosphate } \\ & \text { dehydrogenase } \\ & \text { HF }=\text { heart failure } \\ & \text { HF-CU }=\text { heart failure-complete unloading } \\ & \text { HF-PU }=\text { heart failure-partial unloading } \\ & \text { LAD }=\text { left anterior descending } \\ & \text { LV }=\text { left ventricular } \\ & \text { LVAD }=\text { left ventricular assist device } \\ & \text { LVDd }=\text { left ventricular end-diastolic dimension } \\ & \text { LVEDA }=\text { left ventricular end-diastolic area } \\ & \text { LVESA }=\text { left ventricular end-systolic area } \\ & \text { MI }=\text { myocardial infarction } \\ & \text { PCR }=\text { polymerase chain reaction } \\ & \text { SERCA2a }=\text { sarco(endo)plasmic reticulum } \\ & \text { Ca }{ }^{2+} \text {-ATPase2a }\end{aligned}$

Anterior myocardial infarction (MI) was created by the ligation of LAD near the main pulmonary. Four weeks after the ligation of LAD, LV function and infarct size were evaluated by echocardiography with a $12-\mathrm{MHz}$ phased array transducer (HP SONOS 4500, Agilent Technologies, Andover, MA). B-mode measurement in the LV short axis view (papillary muscle level) was performed. Left ventricular end-diastolic area (LVEDA) and left ventricular end-systolic area (LVESA) were measured by tracing the endocardial border. Fractional area change (FAC), an index of LV systolic function, was calculated by this equation: FAC $(\%)=($ LVEDA - LVESA $) /$ LVEDA $\times$ 100. LV end-diastolic dimension (LVDd) was recorded by M-mode. Infarct size (\%) was calculated as (infarct length in LV diastolic phase)/(LV diastolic circumference) $\times 100$. Three measurements were taken and averaged to calculate these parameters during each examination.

Partial Unloading Model. The donor heart and lungs were harvested after ligation of left and right superior vena cava and the inferior vena cava and transection of the ascending aorta and the trachea. The ascending aorta of the donor heart was anastomosed end-to-side to the abdominal aorta of the recipient. Once the abdominal aorta was declamped, the donor heart was perfused through the coronary arteries and started beating. Only the coronary venous blood entered the left ventricle through the coronary sinus, the right atrium, the right ventricle, the pulmonary artery, the lungs, the pulmonary veins, and the left atrium. Therefore, the left ventricle was partially unloaded.

Complete Unloading Model. The donor heart was harvested after ligation of the pulmonary veins and both vena cava and transection of the ascending aorta and main pulmonary artery. The ascending aorta of the donor heart was anastomosed end-to-side to the abdominal aorta of the recipient, and the pulmonary artery of the donor heart was anastomosed end-to-side to the inferior vena cava of the recipient. Coronary venous blood was drained into the right atrium and the right ventricle and ejected into the pulmonary artery and the recipient inferior vena cava. Thus, left heart cavities were entirely shunted and the left ventricle was completely unloaded.

After heterotopic transplantation, most of the rats survived with an operative mortality of less than $5 \%$.

\section{Study Protocol}

Four weeks after the ligation of LAD, rats with HF (infarct size $>30 \%$ ) were randomly divided into 3 groups: in the HF-partial unloading group (HF-PU group, $\mathrm{n}=8$ each), the infarcted hearts and lungs were heterotopically transplanted into the abdomen of recipient rats; in the HF-complete unloading group (HF-CU, $\mathrm{n}=7$ each), the infarcted hearts were heterotopically transplanted into the abdomen of recipient rats; in the HF group $(n=8$ each), the hearts were not transplanted. Animals were studied at either 2 weeks or 4 weeks after transplantation. Normal rats were used as controls (control group, $\mathrm{n}=7$ ).

\section{Isolated Papillary Muscle Function}

Papillary muscle function was examined at experimental end points as described elsewhere. ${ }^{8}$ Rats were anesthetized with pentobarbital sodium $(100 \mathrm{mg} / \mathrm{kg})$ via intraperitoneal injection and heparinized (500 U) via intravenous infusion. After opening the abdomen, the heart was quickly excised and placed into normal Tyrode's solution containing (in mmol/L) $\mathrm{Na}^{+} 142$, $\mathrm{K}^{+} 5.6, \mathrm{Mg}^{2+} 1, \mathrm{Cl}^{-}$154.6, HEPES 5, and glucose 11 . Noninfarcted posterior papillary muscle was carefully ligated with a silk thread, dissected from the LV wall, and mounted in a tissue bath containing Krebs-Henseleit solution (in $\mathrm{mmol} / \mathrm{L}$ ) $\mathrm{Na}^{+} 152, \mathrm{~K}^{+} 3.6, \mathrm{Mg}^{2+} 0.6, \mathrm{Ca}^{2+} 2.5, \mathrm{Cl} 135, \mathrm{HCO}_{3}{ }^{-} 25$, $\mathrm{H}_{2} \mathrm{PO}_{4}^{-}$1.3, $\mathrm{SO}_{4}{ }^{2-} 0.6$, glucose 5.6, and 2, 3-butanedione monoxime 30, $\mathrm{pH}$ 7.4. The bath was maintained at a constant temperature of $37^{\circ} \mathrm{C}$ and bubbled with $95 \% \mathrm{O}_{2}$ and $5 \% \mathrm{CO}_{2}$. The papillary muscle was stimulated at 1 $\mathrm{Hz}$ with impulses of 5-ms duration by use of field stimulation delivered through a pair of electrodes placed parallel to the muscle. Five-millisecond pluses at a voltage approximately $10 \%$ above threshold level were used. The papillary muscle was stretched to the length at which maximal tension occurred. After stabilization, isometric tension was recorded digitally at the maximum tension position, and papillary muscle diameter was measured with a calibrated eyepiece. Isometric contraction parameters of 10 twitches were averaged and development tension (DT) was normalized for muscle cross-sectional area in square millimeters.

After baseline measurements were finished, DT was recorded during exposure to the $\beta$-adrenergic agonist isoproterenol. Isoproterenol $\mathrm{HCl}$ was dissolved in perfusate to produce cumulative concentrations of $10^{-8}$ and $10^{-7} \mathrm{~mol} / \mathrm{L}$. DT was measured when the response was maximal.

After removal of the papillary muscle from the heart, the LV myocardium was transversely sliced into 2-mm-diameter sections at the base of the papillary muscle and fixed in $10 \%$ buffered formalin. The remaining $\mathrm{LV}$ myocardium was frozen at $-80^{\circ} \mathrm{C}$ until analyzed.

\section{Determination of Cardiomyocyte Diameter and Analysis of mRNA Expression}

Transverse sections of LV myocardium were stained with hematoxylineosin to measure cardiomyocyte diameter. The mean cardiomyocyte diameters were calculated by measurement of 50 cells in the remote area of infarction under microscopy (magnification $\times 400$ ) to avoid the direct influence of myocardial necrosis and fibrosis. Cells were accepted for measurement if they met the following criteria: (1) cross sections of cardiomyocytes were present, (2) cardiomyocytes had a visible nucleus, and (3) their cellular membranes were intact. ${ }^{5}$

Expression of specific mRNA was determined using the ABI PRISM 7700 sequence detection system (Applied Biosystems, Warrington, UK). Polymerase chain reaction (PCR) conditions were 40 cycles of denaturing at $94^{\circ} \mathrm{C}$ for 20 seconds and primer annealing/extension at $62^{\circ} \mathrm{C}$ for $60 \mathrm{sec}-$ onds. The PCR sequences of brain natriuretic peptide (BNP), sarco(endo)plasmic reticulum $\mathrm{Ca}^{2+}$-ATPase2a (SERCA2a), and $\beta_{1^{-}}$and $\beta_{2}$-adrenergic receptors (ARs) were previously reported in our studies. ${ }^{5,8}$ The TaqMan rodent glyceraldehyde 3-phosphate dehydrogenase (GAPDH) control reagent was used to detect rat GAPDH as the internal standard. Expression levels of the target gene were normalized to the GAPDH level in each sample. 
TABLE 1. Baseline echocardiographic data

\begin{tabular}{|c|c|c|c|c|c|c|c|}
\hline & $\begin{array}{c}\text { Control } \\
(n=7)\end{array}$ & $\begin{array}{c}\text { HF (2 wk), } \\
\quad n=8\end{array}$ & $\begin{array}{c}\text { HF-PU (2 wk), } \\
\quad n=8\end{array}$ & $\begin{array}{c}\text { HF-CU (2 wk), } \\
\quad n=7\end{array}$ & $\begin{array}{c}\text { HF (4 wk), } \\
\quad n=8\end{array}$ & $\begin{array}{c}\text { HF-PU (4 wk), } \\
n=8\end{array}$ & $\begin{array}{c}\text { HF-CU (4 wk) } \\
n=7 \\
\end{array}$ \\
\hline $\operatorname{LVDd}(\mathrm{cm})$ & $0.65 \pm 0.09$ & $0.94 \pm 0.05^{*}$ & $0.96 \pm 0.07 *$ & $1.01 \pm 0.06^{*}$ & $0.96 \pm 0.04 *$ & $0.95 \pm 0.03 *$ & $0.98 \pm 0.09^{*}$ \\
\hline FAC $(\%)$ & $58.32 \pm 3.61$ & $32.71 \pm 2.14^{*}$ & $30.35 \pm 2.54 *$ & $31.26 \pm 1.59 *$ & $31.05 \pm 3.24^{*}$ & $32.71 \pm 3.59 *$ & $31.71 \pm 1.82^{*}$ \\
\hline Infarct size $(\%)$ & 0 & $31.27 \pm 1.74^{*}$ & $31.58 \pm 1.24 *$ & $30.36 \pm 1.13 *$ & $31.37 \pm 1.48^{*}$ & $30.96 \pm 1.62 *$ & $31.23 \pm 1.27 *$ \\
\hline
\end{tabular}

$H F$, Heart failure; $P U$, partial unloading; $C U$, complete unloading; $L V D d$, left ventricular end-diastolic dimension; $F A C$, fractional area change. $* P<.05$ versus control group.

\section{Data Analysis}

All data are expressed as means \pm standard deviations. Differences among groups were evaluated by one-way analysis of variance (ANOVA) followed by a post hoc test. Two-way ANOVA with repeated measures was used to assess the inotropic response to isoproterenol. Statistical analyses were performed using Statview for Windows version 5.0 (SAS Institute Inc, Cary, NC). Statistical significance was accepted at the level of $P<.05$.

\section{RESULTS}

\section{Assessment of HF Baseline Echocardiographic Data}

The baseline echocardiographic data are shown in Table 1. Four weeks after the ligation of LAD, LVDd and FAC were significantly impaired in the HF, HF-PU, and HF-CU groups compared with the control group. There were no significant differences at baseline and at pretreatment in LVDd, FAC, and MI size among the HF, HF-PU, and HF$\mathrm{CU}$ groups before transplantation.

\section{Weight and Cardiomyocyte Diameter}

LV weight and cardiomyocyte diameter (Table 2) were lower in both the HF-PU and HF-CU groups than in the $\mathrm{HF}$ group at 2 weeks after transplantation, and there were no statistical differences with the control group. At 4 weeks after transplantation, they were also lower in both the HF-PU and HF-CU groups than in the HF group. However, histologic finding showed that cardiomyocyte became atrophied in the HF-CU group and remained at normal level in the HF-PU group.

\section{Baseline DT and $\beta$-adrenergic Responsiveness of Isolated Papillary Muscle}

Average contractility of papillary muscle at baseline is presented in Table 2. At 2 weeks after transplantation, DTs were higher in both the HF-PU and HF-CU groups than in the HF group, and there were no statistical differences with the control group. But at 4 weeks after transplantation, DT in both the HF-PU and HF-CU groups were lower than in the control group. The inotropic response to isopro- terenol is shown in Figure 1. At 2 weeks after transplantation, the increase from baseline in DT produced by $\beta$-adrenergic stimulation (isoproterenol $10^{-8}$ and $10^{-7} \mathrm{~mol} /$ L) was improved in papillary muscle from the HF-PU group, but there were no statistical differences with the HF-CU and $\mathrm{HF}$ groups. At 4 weeks after transplantation, the increase was significantly improved in the HF-PU group compared with muscles from the HF-CU and HF groups (isoproterenol $10^{-8} \mathrm{~mol} / \mathrm{L}: 25.64 \% \pm 10.11 \%$ vs $13.63 \% \pm 4.63 \%$ and $10.51 \% \pm 4.35 \%, P<.05$ ) and (isoproterenol $10^{-7} \mathrm{~mol} /$ L: $33.39 \% \pm 20.17 \%$ vs $10.12 \% \pm 4.45 \%$ and $11.54 \%$ $\pm 6.66 \%, P<.05)$.

\section{Myocardial Expressions of BNP and SERCA2a mRNAs}

The mRNA expression of BNP (Table 3) was lower in both the HF-PU and HF-CU groups than in the HF group at 2 weeks after transplantation, and there were no statistical differences with the control group. However, this expression was higher in the HF-CU group than in the HF-PU and control groups at 4 weeks after transplantation. In contrast, there was no statistical difference between the HF-PU and control groups.

At 2 weeks after transplantation, the SERCA2a expression (Table 3) was higher in both the HF-PU and HF-CU groups than in the HF group, and there were no statistical differences with the control group. At 4 weeks after transplantation, it was lower in both the HF-PU and HF-CU groups than in the control group.

\section{Myocardial Expressions of $\beta_{\mathbf{1}^{-}}$and $\boldsymbol{\beta}_{\mathbf{2}}$-ARs mRNAs}

As shown in Table 3, at 2 and 4 weeks after transplantation, the mRNA expression of $\beta_{1}$-AR was higher in the HF-PU group than in the HF-CU and HF groups. The mRNA expression of $\beta_{2}$-AR was normalized in the HF-PU and HF-CU groups at 2 weeks after transplantation (Table $3)$. However, at 4 weeks after transplantation, $\beta_{2}-\mathrm{AR}$

TABLE 2. LV weight, myocyte diameter, and developed tension

\begin{tabular}{|c|c|c|c|c|c|c|c|}
\hline & $\begin{array}{l}\text { Control } \\
(n=7)\end{array}$ & $\begin{array}{c}\text { HF (2 wk), } \\
\quad n=8\end{array}$ & $\begin{array}{c}\text { HF-PU (2 wk), } \\
n=8\end{array}$ & $\begin{array}{c}\text { HF-CU (2 wk), } \\
n=7\end{array}$ & $\begin{array}{c}\text { HF (4 wk), } \\
\quad n=8\end{array}$ & $\begin{array}{c}\text { HF-PU (4 wk), } \\
n=8\end{array}$ & $\begin{array}{c}\text { HF-CU (4 wk), } \\
n=7\end{array}$ \\
\hline LV weight (g) & $0.57 \pm 0.04$ & $0.85 \pm 0.04 *$ & $0.57 \pm 0.05 \dagger$ & $0.53 \pm 0.06 \dagger$ & $0.81 \pm 0.05^{*}$ & $0.52 \pm 0.05 \dagger$ & $0.46 \pm 0.07 * \dagger$ \\
\hline Myocyte diameter $(\mu \mathrm{m})$ & $19.93 \pm 0.80$ & $27.34 \pm 1.46^{*}$ & $20.17 \pm 1.61 \dagger$ & $18.76 \pm 0.45 \dagger$ & $30.13 \pm 1.37^{*}$ & $19.08 \pm 0.90 \dagger$ & $17.54 \pm 0.84^{*} \dagger$ \\
\hline Developed tension $\left(\mathrm{g} / \mathrm{mm}^{2}\right)$ & $0.21 \pm 0.07$ & $0.02 \pm 0.01 *$ & $0.15 \pm 0.07 \dagger$ & $0.12 \pm 0.05 \dagger$ & $0.01 \pm 0.01 *$ & $0.11 \pm 0.03^{*} \dagger$ & $0.10 \pm 0.03^{*} \dagger$ \\
\hline
\end{tabular}

$H F$, Heart failure; $P U$, partial unloading; $C U$, complete unloading; $L V$, left ventricle. $* P<.05$ versus control group, $\dagger P<.05$ versus $\mathrm{HF}$ group at the same time point. 

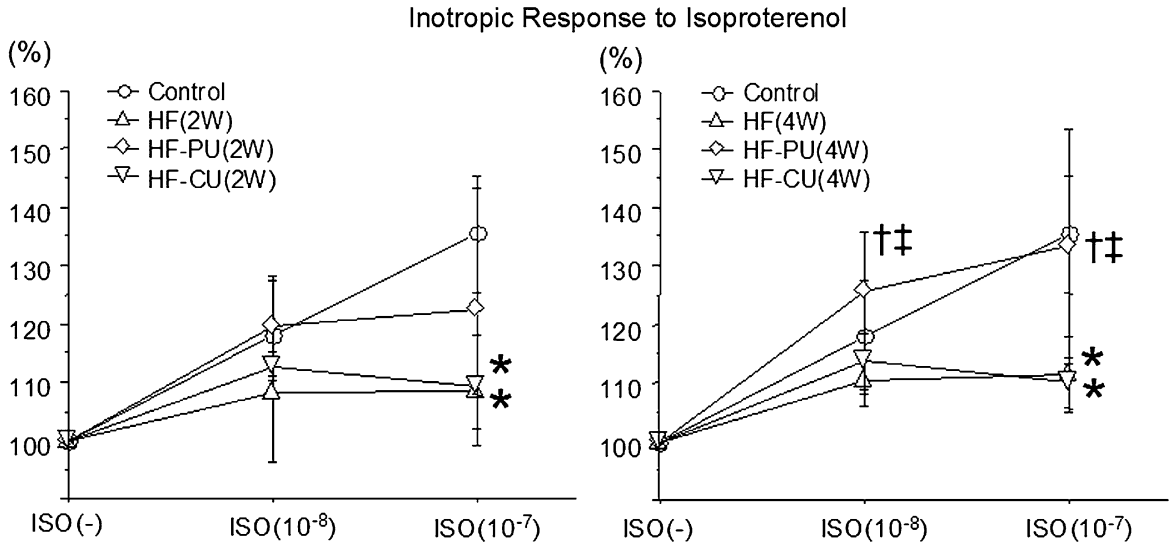

FIGURE 1. Inotropic response to isoproterenol (the increase in developed tension) as a percentage of baseline. $H F$, heart failure; $P U$, partial unloading; $C U$, complete unloading; $W$, weeks. All values are expressed as means \pm standard deviations. ${ }^{*} P<.05$ versus control group; ${ }^{\dagger} P<.05$ versus $\mathrm{HF}$ group; ${ }^{\ddagger} P<.05$ versus HF-CU group.

mRNA expression remained at a normal level in the HF-PU group and lower in the HF-CU group.

\section{DISCUSSION}

Using the 2 heterotopic transplantation models, we compared $\beta$-adrenergic responsiveness of papillary muscles and gene expressions in failing rat hearts under partial and complete unloading. We observed that chronic partial unloading but not complete unloading improved the functional response to $\beta$-adrenergic stimulation by isoproterenol and normalized mRNA expressions of BNP and $\beta_{1^{-}}$and $\beta_{2}$-ARs in failing rat hearts. These data suggest that partial loading helps restore $\beta$-adrenergic responsiveness and reverse mRNA expression downregulation during mechanical unloading. LVAD provides ventricular unloading, and the timing of initiation of the LVAD ejection can control loading and unloading. The counterpulsation mode of LVAD does not allow the native aortic valve to open, and there is no flow through the aortic valve. Therefore, the pump captures the entire cardiac output, and the left ventricle is completely unloaded. The methods of 2 heterotopic transplantation models can create 2 types of unloading situation (partial and complete unloading) of the left ventricle for simulating the LVAD support.

$\beta$-ARs ( $\beta_{1}$ and $\beta_{2}$ subtypes) are the primary myocardial targets of the sympathetic neurotransmitter norepinephrine and the adrenal hormone epinephrine. Activation of $\beta$-ARs in the heart leads to positive chronotropic and inotropic action. ${ }^{9}$ Although long-term inotropic therapy based on enhanced $\beta$-AR stimulation is likely detrimental, $\beta$-AR stimulation remains the most efficient way to enhance cardiac contractile function acutely. Muscles taken from LVAD hearts produced an inotropic response to isoproterenol that was similar to that measured in nonfailing muscles and significantly better than that measured in muscle from failing hearts without LVAD. ${ }^{10}$ Dipla and colleagues ${ }^{11}$ reported that $\beta$-adrenergic responsiveness of isolated myocytes could be recovered after LVAD support. To measure the cardiac inotropic response to $\beta$-adrenergic stimulation by isoproterenol, we used the posterior papillary muscle in this study. As previously demonstrated,${ }^{12}$ the posterior papillary muscle is not infarcted after the ligation of LAD and can be used for functional studies of the noninfarcted myocardium of the rats with MI. Isoproterenol is a nonselective $\beta$-adrenergic agonist, which stimulates both $\beta_{1^{-}}$and $\beta_{2}$-AR. In the present study, we demonstrated that papillary muscle from failing left ventricle under partial unloading produced a significantly better inotropic response to isoproterenol than those from failing left ventricle under complete unloading and failing left ventricle at 4 weeks after transplantation but not at 2 weeks after transplantation. We suggest that chronic partial unloading contributes to the recovery of the inotropic response to $\beta$-adrenergic stimulation in the failing

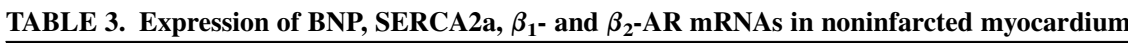

\begin{tabular}{|c|c|c|c|c|c|c|c|}
\hline & $\begin{array}{l}\text { Control } \\
(n=7)\end{array}$ & $\begin{array}{c}\text { HF } \\
(2 w k), n=8\end{array}$ & $\begin{array}{c}\text { HF-PU } \\
(2 \mathrm{wk}), \mathrm{n}=\mathbf{8}\end{array}$ & $\begin{array}{c}\text { HF-CU } \\
(2 \mathrm{wk}), \mathrm{n}=7\end{array}$ & $\begin{array}{c}\text { HF } \\
(4 \mathrm{wk}), n=8\end{array}$ & $\begin{array}{c}\text { HF-PU } \\
(4 \mathrm{wk}), n=8\end{array}$ & $\begin{array}{c}\text { HF-CU } \\
(4 \mathrm{wk}), n=7\end{array}$ \\
\hline BNP/GAPDH & $0.13 \pm 0.02$ & $0.32 \pm 0.08^{*}$ & $0.20 \pm 0.05 \dagger$ & $0.18 \pm 0.07 \dagger$ & $0.49 \pm 0.16^{*}$ & $0.17 \pm 0.04 \dagger \dagger$ & $0.39 \pm 0.12 *$ \\
\hline SERCA2a/GAPDH & $0.15 \pm 0.03$ & $0.11 \pm 0.01 *$ & $0.15 \pm 0.01 \dagger$ & $0.14 \pm 0.01 \dagger$ & $0.07 \pm 0.02^{*}$ & $0.08 \pm 0.02^{*}$ & $0.07 \pm 0.02 *$ \\
\hline$\beta_{1}-\mathrm{AR} / \mathrm{GAPDH}$ & $0.14 \pm 0.03$ & $0.07 \pm 0.02 *$ & $0.13 \pm 0.02 \dagger \ddagger$ & $0.06 \pm 0.02 *$ & $0.06 \pm 0.02 *$ & $0.11 \pm 0.03 \dagger \ddagger$ & $0.05 \pm 0.01 *$ \\
\hline$\beta 2-\mathrm{AR} / \mathrm{GAPDH}$ & $0.12 \pm 0.04$ & $0.07 \pm 0.01 *$ & $0.15 \pm 0.02 \dagger$ & $0.13 \pm 0.04 \dagger$ & $0.06 \pm 0.02 *$ & $0.12 \pm 0.04 \dagger \ddagger$ & $0.04 \pm 0.02 *$ \\
\hline
\end{tabular}

$B N P$, Brain natriuretic peptide; $S E R C A 2 a$, saco(endo)plasmic reticulum $\mathrm{Ca}^{2+}$-ATPase2a; $A R$, adrenergic receptor; $G A P D H$, glyceraldehyde 3-phosphate dehydrogenase; $H F$, heart failure; $P U$, partial unloading; $C U$, complete unloading. ${ }^{*} P<.05$ versus control group; $\dagger P<.05$ versus HF group; $\ddagger P<.05$ versus HF-CU group at the same time point. 
rat hearts. Ogletree-Hughes and colleagues ${ }^{10}$ also demonstrated that patients supported for a longer time had greater recovery of inotropic response, suggesting that factors in addition to duration contribute to variability in recovery of the inotropic response.

We measured the mRNA expressions of $\beta_{1}$ - and $\beta_{2}$-AR in the noninfarcted myocardium. $\beta_{1}$-AR is the predominant subtype, approaching $70 \%$ to $80 \%$ of total $\beta$-ARs, but functional coupling to contractility has been demonstrated for the $\beta_{2}$ subtype. ${ }^{13}$ It is generally accepted that in the process of $\mathrm{HF}$, the density and affinity of $\beta$-ARs are known to decrease and lead to a deterioration in cardiac function. In the present study, we have shown that partial unloading can lead to upregulation of myocardial $\beta_{1}$ - and $\beta_{2}$-AR mRNA expressions to near normal levels. It was thought that the recovery of $\beta$ ARs mRNA was due to hemodynamic factors resulting from the unloading extent of failing left ventricle because only $\beta_{2^{-}}$ AR mRNA expression was improved in failing left ventricle under complete unloading at 2 weeks after transplantation, then it decreased at 4 weeks after transplantation. The differences of $\beta$-AR mRNA expressions suggest that chronic partial unloading can restore both $\beta_{1}$ - and $\beta_{2}$-AR mRNA expressions, resulting in the recovery of inotropic response to $\beta$-adrenergic stimulation by isoproterenol. In our previous study, ${ }^{5}$ only $\beta_{2}$-AR mRNA expression was normalized in failing rat hearts for 2 weeks' complete unloading. Tevaearai and associates ${ }^{14}$ demonstrated that the overexpression of $\beta_{2^{-}}$ AR potentiated the functional recovery of unloaded (complete unloading) failing rabbit hearts. Cardiac $\beta_{2}$-receptor subtype acts preferentially to increase the opening of plasma membrane calcium channels. Overexpression of the $\beta_{2}$-AR resulted in marked enhancement of LV contractility as assessed by the maximal first derivative of LV pressure, $\mathrm{dP} /$ $\mathrm{dt}_{\max }$, compared with negative littermate controls in the transgenic mice. ${ }^{15}$ Recently, $\beta_{2}$-agonist has been shown to have a beneficial effect on LV remodeling after MI in a rat model. ${ }^{16}$ Furthermore, stimulation of cardiac myocyte with $\beta_{2}$-agonist seems to give protection against apoptosis. ${ }^{17}$

In the present study, we also measured the BNP mRNA expression. BNP is a member of the natriuretic peptide family synthesized and secreted in the cardiac ventricle in response to cardiomyocyte stretch. ${ }^{18}$ Increased plasma BNP correlated with LV dilatation or ventricular stiffness. ${ }^{19} \mathrm{We}$ have shown that the mRNA expression of BNP was normalized in both the HF-CU and HF-PU groups at 2 weeks after transplantation, but it remained at the normal level in the HF-PU group but increased in the HF-CU group at 4 weeks after transplantation. Therefore, we suggest that chronic and severe (complete) unloading causes too much reduction of ventricular volume and wall tension, which can impair the functional recovery. We do not know what extent of LV unloading is appropriate for induction of "reverse remodeling" and functional recovery, but we suggest that it is important to keep appropriate LV tension under LVAD support.
Recent clinical reports in some patients with end-stage HF have demonstrated that LVAD can improve cardiac function and be used as a "bridge to recovery" without heart transplantation. ${ }^{2,20}$ However, its success rate as a bridge to recovery is low. ${ }^{21}$ Although our data have shown that chronic partial unloading may result in recovery of $\beta$-adrenergic responsiveness, we also found that both HF-PU and HF-CU caused a time-dependent depression in baseline DT of papillary muscle. DT decreased under the normal levels at 4 weeks after transplantation, although the contractility was significantly improved compared with that of failing hearts. Furthermore, the mRNA expression of SERCA2a also decreased at 4 weeks after transplantation in both the HF-PU and HF-CU groups. Therefore, we suggest that long-term unloading can result in a time-dependent depression of the reversion of contractility and SERCA2a mRNA expression. Some reports have shown similar results. Bartling and colleagues $^{22}$ demonstrated that LV transcription of SERCA2a as well as of $\mathrm{Na}^{+}-\mathrm{Ca}^{2+}$ exchanger remained at failing levels despite LVAD support in some patients. Ito and associates ${ }^{23}$ demonstrated that chronic complete unloading of normal rat hearts caused depression of myocyte contractile reserve and impaired $\left[\mathrm{Ca}^{2+}\right] \mathrm{i}$ handing in association with a reduced SERCA2a-to-phospholamban (PLB) protein ratio. Cardiac unloading by LVAD for a very long duration in patients with HF may induce cardiac atrophy and depress contractility. However, the optimal duration of mechanical unloading was not clear. Xydas and colleagues ${ }^{24}$ demonstrated that cardiac recovery peaked by 60 days, and echocardiography, electrocardiography, histology, and neurohormone were improved during LVAD support.

This study has some limitations. First, heterotopic transplantation necessitates an organ harvest, a short duration of cardiac ischemia, and surgical implantation in another rat. We should consider the influence of ischemia during cardiac arrest. All transplantation procedures took $<40$ minutes, and we used cold cardioplegic solution and ice protection during the procedures. Thus, we believed the ischemic influences would be minimal. Second, we chose to study the isolated posterior papillary muscle to assess the myocardial functional "recovery" of failing hearts. The effects of unloading are thought to encompass not only changes at the cellular level but also regional and global function as part of the remodeling process. Therefore, whether the results of papillary muscle can reflect the global LV function precisely is unknown. Third, in this study, the mRNA levels were measured, not the protein levels. Therefore, it is undetermined whether the alteration of mRNA precisely reflected protein expression. Finally, as transplantation technique renders the grafted heart denervated, $\beta$-AR might be influenced by the absence of direct neural stimulation rather than unloading. A previous report has suggested that restoration of $\beta$-AR density is independent of cardiac denervation. ${ }^{14}$ Therefore, we believe that the improvement of $\beta$-AR 
mRNA expression appears to be due to unloading rather than denervation.

In summary, we have shown that chronic partial unloading but not complete unloading of failing rat hearts results in recovery of the ability of papillary muscle to respond to $\beta$-adrenergic stimulation by isoproterenol and normalizes BNP and $\beta_{1^{-}}$and $\beta_{2}$-AR mRNA expressions. The differences of inotropic response and mRNA expressions may be related to the extent of unloading of failing rat hearts. The present study also showed a time-dependent depression in baseline contractility of papillary muscle both in partial and complete unloading, which may have a relation with the trend toward myocyte atrophy and downregulation of SERCA2a mRNA expression.

We thank Mrs. F. Kataoka for her histologic assistance.

\section{References}

1. Frazier OH, Benedict CR, Radovancevic B, Bick RJ, Capek P, Springer WE, et al. Improved left ventricular function after chronic left ventricular unloading. Ann Thorac Surg. 1996;62:675-81.

2. Hetzer R, Muller J, Weng Y, Wallukat G, Spiegelsberger S, Loebe M. Cardiac recovery in dilated cardiomyopathy by unloading with a left ventricular assist. Ann Thorac Surg. 1999;68:742-9.

3. Muller J, Wallukat G, Weng YG, Dandel M, Spiegelsberger S, Semrau S, et al. Weaning from mechanical cardiac support in patients with idiopathic dilated cardiomyopathy. Circulation. 1997;96:542-9.

4. Tevaearai HT, Walton GB, Eckhart AD, Keys JR, Koch WJ. Heterotopic transplantation as a model to study functional recovery of unloaded failing hearts. J Thorac Cardiovasc Surg. 2002;124:1149-56.

5. Tsuneyoshi H, Oriyanhan W, Kanemitsu H, Shiina R, Ikeda T, Nishimura K, Komeda M. Heterotopic transplantation of the failing rat heart as a model of left ventricular mechanical unloading toward recovery. ASAIO J. 2005;51: 116-20.

6. Mizuno T, Weisel RD, Li RK. Reloading the heart: a new animal model of left ventricular assist device removal. J Thorac Cardiovasc Surg. 2005; 130:99-106.

7. Wang J, Marui A, Ikeda T, Komeda M. Partial left ventricular unloading reverses contractile dysfunction and helps recover gene expressions in failing rat hearts. Interact Cardiovasc Thorac Surg. 2008;7:27-31.

8. Tsuneyoshi H, Oriyanhan W, Kanemitsu H, Shiina R, Nishina T, Matsuoka S, et al. Does the beta2-agonist clenbuterol help to maintain myocardial potential to recover during mechanical unloading? Circulation. 2005;112:I51-6.

9. Brodde OE. Beta-adrenergic receptors in failing human myocardium. Basic Res Cardiol. 1996;91:S35-40.
10. Ogletree-Hughes ML, Stull LB, Sweet WE, Smedira NG, McCarthy PM, Moravec CS. Mechanical unloading restores beta-adrenergic responsiveness and reversed receptor downregulation in the failing human heart. Circulation. 2001;104:881-6.

11. Dipla K, Mattiello JA, Jeevanandam V, Houser SR, Margulies KB. Myocyte recovery after mechanical circulatory support in humans with end-stage heart failure. Circulation. 1998;97:2316-22.

12. Litwin SE, Litwin CM, Raya TE, Warner A, Goldman S. Contractility and stiffness of noninfarcted myocardium following coronary ligation in rats: effects of chronic angiotension converting enzyme inhibition. Circulation. 1991;83:1082-7.

13. Rockman HA, Koch WJ, Milano CA, Lefkowitz RJ. Myocardial beta-adrenergic receptor signaling in vivo: insights from transgenic mice. J Mol Med. 1996;74: 489-95.

14. Tevaearai HT, Eckhart AD, Walton GB, Keys JR, Wilson K, Koch WJ. Myocardial gene transfer and overexpression of beta2-adrenergic potentiates the functional recovery of unloaded failing hears. Circulation. 2002;106:124-9.

15. Milano CA, Allen LF, Rockman HA, Dolber PC, McMinn TR, Chien KR, et al. Enhanced myocardial function in transgenic mice overexpressing the beta2-adrenergic receptor. Science. 1994;264:582-6.

16. Ahmet I, Krawczyk M, Heller P, Moon C, Lakatta EG, Talan MI. Beneficial effects of chronic pharmacological manipulation of beta-adrenoreceptor subtype signaling in rodent dilated ischemic cardiomyopathy. Circulation. 2004;110: 1083-90.

17. Communal C, Colucci WS. The control of cardiomyocyte apoptosis via the betaadrenergic signaling pathways. Arch Mal Coeur Vaiss. 2005;98:236-41.

18. Maisel AS, Krishnaswamy P, Nowak RM, McCord J, Hollander JE, Duc P, et al. Rapid measurement of B-type natriuretic peptide in the emergency diagnosis of heart failure. N Engl J Med. 2002;347:161-7.

19. Kawakami P, Saito Y, Kishimoto I, Harada M, Kuwahara K, Takahashi N, et al. Overexpression of brain natriuretic peptide facilitates neutrophil infiltration and cardiac matrix metalloproteinase- 9 expression after acute myocardial infarction. Circulation. 2004;110:3306-12.

20. Heerdt PM, Holmes JW, Cai B, Barbone A, Madiqan JD, Reiken S, et al. Chronic unloading by left ventricular assist device reverses contractile dysfunction and alters gene expression in end-stage heart failure. Circulation. 2000;102: 2713-9.

21. Mancini DM, Beniaminovitz A, Levin H, Catanese K, Flannery M, DiTullio M, et al. Low incidence of myocardial recovery after left ventricular assist device implantation in patients with chronic heart failure. Circulation. 1998;98:2383-9.

22. Bartling B, Milting H, Schumann H, Darner D, Arusoglu L, Koerner MM, et al. Myocardial gene expression of regulators of myocyte apoptosis and myocyte calcium homeostasis during hemodynamic unloading by ventricular assist devices in patients with end-stage heart failure. Circulation. 1999;100:II216-23.

23. Ito K, Nakayama M, Hasan F, Yan X, Schneider MD, Lorell BH. Contractile reserve and calcium regulation are depressed in myocytes from chronically unloaded hearts. Circulation. 2003;107:1176-82.

24. Xydas S, Rosen RS, Ng C, Mercando M, Cohen J, DiTullio M, et al. Mechanical unloading leads to echocardiographic, electrocardiographic, neurohormonal, and histologic recovery. J Heart Lung Transplant. 2006;25:7-15. 